\title{
Proyecto para un repertorio digital de grabados en libros (siglos XV-XVIII)
}

\author{
Project for a digital repertory of engravings in books $\left(15^{\text {th }}-18^{\text {th }}\right.$ centuries)
}

\begin{abstract}
Cristina Herrero Pascual (1) y Pedro Díaz Ortuño (2)
Departamento de Información y Documentación, Facultad de Biblioteconomía y Documentación, Universidad de Murcia, Campus de Espinardo, Aptdo. 4201, 30071 Murcia. (1) herrepas@um.es
\end{abstract}

(2) diazor@um.es

\begin{abstract}
Resumen
Presentamos un proyecto de investigación bibliográfica y documental que consiste en recoger, inventariar, analizar y difundir vía digital las ilustraciones contenidas en los impresos (libros, folletos, papeles sueltos, etc.) de los siglos XV al XVIII que se encuentran depositados en las bibliotecas de la Región de Murcia. El objetivo general es la difusión de una información de difícil acceso, los grabados, aprovechando las tecnologías de la información. Para ello se han establecido como objetivos parciales los de localizar, identificar, digitalizar, describir y difundir los grabados. Para conseguir estos objetivos se ha diseñado una metodología propia estructurada en tres fases sucesivas: digitalización, descripción y gestión de la base de datos. El resultado es un repertorio digital de grabados de libros que permite su recuperación por autor, título, descriptores, fuente, impresor, fecha y otros elementos. Este repertorio va a mejorar el acceso a la información y supone una nueva experiencia en la aplicación de metadatos en la descripción de imágenes, cuya eficacia habrá que evaluar.
\end{abstract}

Palabras clave: Grabados de libros. Digitalización de documentos. Análisis de imágen. Bibliotecas digitales. Formatos de ficheros.

\section{Introducción}

Este proyecto, en su fase inicial actualmente, se enmarca en las políticas de difusión del patrimonio bibliográfico y documental a la luz de las nuevas tecnologías de la información. La estructura del Estado en Comunidades Autónomas que estableció la Constitución de 1978 hizo florecer los estudios autonómicos y regionales en muchos campos, y nosotros nos vamos a centrar en el patrimonio bibliográfico de la Región de Murcia.

Se entiende por éste la colección de documentos textuales, sonoros, gráficos, audiovisuales o multimedia, tanto publicados como inéditos, antiguos o modernos que se conservan en las bibliotecas de la Región de Murcia. Dichos fondos están todos catalogados en las bibliotecas

\begin{abstract}
We present a project of bibliographical and documental research that consists in collecting, classifying, analyzing and digitally diffusing the illustrations contained in the printed matters (books, pamphlets, loose papers, etc.) from the fifteenth to the eighteenth centuries that are deposited in the libraries of the Region of Murcia. The general aim is the diffusion of information of difficult access, i.e. the engravings, taking advantage of the information technologies. We have established as partial objectives those of locating, identifying, digitizing, describing and disseminating the engravings. In order to achieve these objectives, a specific methodology has been devised, and accomplished in three successive phases: digitization, description and database management,. The result is a digital book engravings repository that allows for their retrieval by author, title, keywords, source, publisher, dates and other elements. This repository will improve the access to the information and it marks a new experience in metadata application for the description of images, whose effectiveness we will evaluate in a future phase.
\end{abstract}

Keywords: Books engravings. Document digitization. Image analysis. Digital libraries. File formats.

que los custodian y son accesibles a través de los catálogos que se pueden consultar en Internet. Pero los catálogos describen unidades bibliográficas completas, es decir obras que a menudo están compuestas por distintos elementos relacionados entre ellos, como sucede con el texto y la imagen.

Se entiende por grabado el resultado de la estampación sobre papel, o materia análoga, de una plancha en la que de forma manual se ha ejecutado por incisión, talla o dibujo una composición en algún grado artística. Se le denomina también estampa y lámina.

Las imágenes impresas son simultáneas a la generalización de la imprenta en la segunda mitad del siglo XV. Antes de ésta se usaban tacos xilográficos para imprimir imágenes reli- 
giosas sueltas para usos de devoción y también naipes. Cuando se empiezan a imprimir con tipos móviles los textos de los primeros libros, la imagen es un complemento ilustrativo de éste en todo tipo de obras. La técnica del grabado se perfecciona y desarrolla a la vez que la imprenta primitiva hasta que en el siglo XIX aparecen los sistemas mecánicos de estampación.

El objetivo de este trabajo es localizar, identificar, digitalizar, describir y difundir mediante un repertorio digital todos los grabados que hay en libros depositados en bibliotecas de Murcia, aunque se ha empezado por la Biblioteca Universitaria. La ilustración del libro puede ser estudiada desde dos vertientes distintas. Una, en función de las grandes corrientes artísticas, intelectuales y sociales de cada época, de las cuales está influenciada en gran medida, pero este aspecto escapa a los objetivos de un trabajo bibliográfico. La otra, en función de las necesidades de las propias ediciones y de las del público al que van destinados.

Partiendo de la segunda premisa, lo que presentamos es un proyecto de investigación bibliográfica y documental realizado utilizando herramientas actuales de gestión de información, cuyo resultado final va a ser un instrumento de almacenamiento y recuperación de información preciso y fiable. Ello implica el desarrollo de una metodología que incluye técnicas de digitalización, análisis de imagen, formatos digitales de descripción y difusión de la información digital.

El ámbito temporal abarca los siglos XV a XVIII, fechas que comprenden el denominado "fondo antiguo". Las actuaciones relacionadas con estos fondos no son nuevas. La dispersión topográfica de los libros antiguos, ya que están depositados en bibliotecas de todo el mundo independientemente de cual sea su origen, y las dificultades que han tenido su préstamo, prohibido, y su reproducción, muy limitada en aras de su conservación, han hecho que sean el objeto prioritario de los sistemas de difusión no tradicionales. Las ediciones facsímiles, las microformas y la fotocopia han permitido acceder a ellos cuando la observación directa no era posible. Las nuevas tecnologías también han facilitado las reproducciones de documentos y la proliferación de bibliotecas digitales no es más que la evolución natural del tema.

Los antecedentes de este proyecto son varios. Desde el punto de vista de la difusión, podemos partir del programa Control Bibliográfico Universal promovido por la IFLA desde 1974 a 2003 con el objetivo de controlar la producción bibliográfica de todo el mundo mediante un siste- ma cooperativo en el que las bibliotecas nacionales de cada país describieran su producción bibliográfica y la difundieran a través de las bibliografías nacionales. Desde la perspectiva de la investigación bibliográfica, se han hecho repertorios de grabados en muchos países. Hay que destacar en España el repertorio de Elena Páez (1981-1983) y la obra de Lyell (1997). Mención especial merece la obra de García Vega (1984), porque hace un profundo estudio del grabado en libros antiguos depositados en bibliotecas de Valladolid, lo que puede servir de guía a este proyecto basado en grabados en bibliotecas murcianas.

La publicación electrónica ha animado a muchas bibliotecas a ofrecer en sus páginas web repertorios de elementos diversos de los libros que poseen. Marcas tipográficas (Biblioteca Nazionale Centrale di Roma; Universitat de Barcelona; University of Florida), filigranas de papel (Nacional Library of the Netherlands) o grabados (Universidad de Sevilla) ya se pueden buscar en Internet.

\section{Metodología}

El trabajo se realiza en tres fases sucesivas, digitalización, descripción y gestión de la base de datos.

La digitalización se ha iniciado con la localización de las obras con grabados que hay en la Biblioteca Universitaria de Murcia. Se hizo una búsqueda por siglos de todos los registros que incluyeran las palabras ilustración o grabado, con formato de salida en orden topográfico, para poder ver los libros siguiendo el orden que tienen en las estanterías. A partir de estos listados y de la observación directa de los libros, se han seleccionado los grabados que había que digitalizar que, en principio, son todos.

Hemos tenido en cuenta el criterio de McKerrow (1998, p. 137) para diferenciar entre ilustración y decoración en los libros. Por esta razón, se han excluido las marcas tipográficas y elementos tipográficos como iniciales y viñetas. Creemos que las marcas pueden constituir un repertorio propio dado su número, variedad y la información que ofrecen para identificar y localizar a los impresores y las relaciones entre ellos. Además, las marcas tipográficas están disponibles en la Biblioteca de Portadas y Colofones, Siglos XVIXVIII, que forma parte de la Biblioteca Universitaria de Murcia. La inclusión de viñetas, iniciales y otros elementos tipográficos hubiera prolongado el trabajo dado su elevado número. Pero sí se han recogido las cabeceras, la mayoría de ellas calcográficas, que contenían escenas o imágenes decorativas. Del resto de grabados 
solo se han desechado los que su estado de deterioro impedía apreciar su contenido.

Para digitalizar las obras, se ha aprovechado que la Biblioteca Universitaria está en proceso de digitalización de todo el fondo antiguo y tiene un equipo para ello. Dos personas que trabajan para la biblioteca se han incorporado a este proyecto en calidad de alumnos internos del Departamento de Información y Documentación. Las características generales del software y hardware utilizado en la digitalización se incluyen en la tabla siguiente.

\begin{tabular}{|c|c|}
\hline & $\begin{array}{l}\text { Ordenador de altas prestaciones, con gran } \\
\text { capacidad y velocidad de disco duro, con un } \\
\text { mínimo de } 2 \mathrm{~Gb} \text { de memoria RAM, pantalla } \\
\text { de } 19 \text { pulgadas, lector de tarjetas,... } \\
\text { TV de mínimo } 19 \text { pulgadas. } \\
\text { Máquina fotográfica compacta, } 6 \\
\text { megapixeles, con zoom } 4 \mathrm{X} \text {, escala de } \\
\text { blancos, visualización directa en pantalla de } \\
\text { TV, estabilizador de imagen,... } \\
\text { Dos tarjetas de un mínimo de } 256 \mathrm{Mb} \text { cada } \\
\text { una. }\end{array}$ \\
\hline 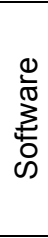 & $\begin{array}{l}\text { Tratamiento digital: Photoshop. } \\
\text { Acrobat Writer 7.0: Montaje de PDF y } \\
\text { optimización de ficheros. } \\
\text { Formatos de imagen: JPG de alta resolución } \\
\text { y PDF multipáginas. } \\
\text { Visualizador de imágenes: Irfanview }\end{array}$ \\
\hline
\end{tabular}

Tabla I. Hardware y software utilizado

Para hacer la descripción se ha diseñado un formato de recogida de datos basado en el estándar de metadatos Dublin Core ya que el producto final es un conjunto de registros codificados en lenguaje XML. Para la elección de los campos de datos, se ha tenido en cuenta la especifidad de la información a recoger referente a los grabados. Según Vives Piqué (2003), en un grabado hay que examinar los aspectos técnicos (xilografía, calcografía), formales (plancha, márgenes, medidas, inscripciones), materiales (papel, tinta), procesuales (tiraje, numeración, edición) y conservación. En este proyecto hemos prescindido de los aspectos materiales, porque, al ser todos los grabados de libros, el material es siempre el papel. Tampoco reseñamos el estado de conservación, pues al reproducir la imagen se puede apreciar directamente, pero incluimos la técnica diferenciando entre xilografías y calcografías. Nos hemos centrado en la descripción la imagen que se representa, lo que en documentación se llama análisis de contenido que, en este caso, es análisis de imagen. También hemos añadido los datos de localización del grabado en la obra y en la biblioteca, su relación con los impresores y las referen- cias bibliográficas de las obras en que han sido citados anteriormente que pueden incluir la fuente de identificación de la imagen.

Toda esta información se está procesando en una base de datos utilizando el sistema de gestión documental Knosys, que combina la facilidad de uso con la satisfacción de todas las prestaciones que requiere el proyecto. Knosys, una base de datos multimedia, que permite tener asociadas imágenes a los registros, con una llamada hipertextual que, al activarla, muestra la imagen. El uso de la base de datos Knosys facilita la búsqueda de texto libre en todos los campos, por lo que no es preciso ceñir la búsqueda a un campo concreto. La introducción de la información es rápida con este sistema, ya que permite introducir gran cantidad de texto en cualquier campo, y no es necesario delimitar previamente la longitud del mismo. También permite el control de la información mediante el uso de listas de términos admitidos.

La base de datos creada con Knosys para la gestión de las imágenes se ha estructurado según los elementos de metadatos que establece el estándar Dublín Core ya que éste va a ser el formato final del repertorio. Para identificar con precisión cada uno de los elementos, nos hemos basado en la tabla de correspondencias entre los campos del formato MARC21 y los elementos de Dublín Core (DC) (Library of Congress). A la hora de dar contenido a cada uno de los elementos, hemos utilizado el Library Application Profile (LAP) (Dublin Core Metadata Initiative), ya que es específico para el ámbito de las bibliotecas. Describimos a continuación cada uno de sus elementos y su contenido, cuya información resumida se ofrece en la Tabla I que aparece al final de este trabajo.

1. Título (Title). Si la imagen se presenta con un título se registra textualmente y entrecomillado como "Título propio". Muchos grabados no llevan título y en estos casos se redacta un "Título asignado acorde con su contenido. Este título es equivalente a un resumen de contenido porque se intenta describir en pocas palabras lo que la imagen representa, ya que una descripción más amplia se realiza en el campo "Descriptores". La redacción del título se hace mediante la observación directa de la imagen cuando está claro lo que representan (Crucifixón, San Antonio). Pero la identificación no siempre es tan fácil. Algunas escenas se refieren a hechos que hay que contrastar en la Biblia, en fuentes históricas o en repertorios de grabados donde ya están descritas. Para los nombres de personas, hechos y lugares conocidos, se está aplicando control de autoridades. 
2. Autor o creador (Creator). Este elemento no tienen contenido en la fase actual del repertorio, porque se ha incluido a los responsables del contenido del documento en el elemento "Colaborador". Esta decisión está avalada por el LAP de Dublin Core que no contempla este elemento y presenta al "Contributor" como segundo elemento, a continuación del título.

3. Materia y palabras clave (Subject). EI LAP de DC describe este elemento como "tema o materia del recurso que puede ser expresada mediante palabras clave, frases o un código de clasificación" y recomienda la utilización de un vocabulario controlado o un esquema de clasificación. Hemos incluido en este elemento la identificación del contenido de la imagen mediante una serie de categorías establecidas para este proyecto que constituyen el tesauro. Éste se va generando conforme avanza del trabajo, pero no es fijo, los términos se pueden modificar y hacer más específicos según las necesidades de gestión. Las técnicas documentales de análisis de la imagen hacen la distinción entre connotación, que es lo que se ve en la imagen, y denotación, que son las sensaciones que evoca la imagen, como tristeza, peligro, alegría, etc (Valle, 1993; Prendes, 1998). Hemos utilizado solo el primer criterio, dada la simplicidad de la mayoría de las ilustraciones, producidas siempre en relación con los textos a los que acompañan. Excepcionalmente, se han incluido los términos "viento" y "noche", claramente denotativos, ante la expresividad de los grabados donde aparecían.

Hasta el momento las categorías establecidas son: ángeles, animales (león), armas, astronomía, banderas, barcos, civiles, demonios, edificios, elementos decorativos, fuego, Jesucristo, libros, liturgia (inciensario), mares, muebles, mujeres, música (arpa), niños, noche, obispos, oficios, paisajes, peces, plantas, religiosos, reyes, ríos, santos (y profetas), utensilios (y máquinas), vajilla, vestidos, viento, y Virgen María

Se intenta no repetir la información contenida en el elemento Título, de manera que si en éste aparece "Retrato de Santo Tomás de Aquino", en descriptores aparece "Santos".

4. Descripción (Description). Este elemento del Dublin Core puede contener el sumario del documento u otra información equivalente a la que se incluye en los campos $5 \mathrm{XX}$ del formato MARC. Ateniéndonos a la tabla de correspondencia entre estos dos formatos publicada por la Library of Congress, utilizamos este campo con criterios distintos que dan lugar a tres elementos de Descripción:
- Nota de "En:", equivalente al campo 501 de MARC21, donde se describe la obra de la que forma parte el grabado mediante la referencia bibliográfica obtenida en el catálogo de la biblioteca propietaria del libro.

- Fecha del grabado, información que aparece en muy pocos casos, pero que interesa registrarla para saber las veces que se ha utilizado la composición. No tiene porque coincidir con la Fecha de publicación que es la de la obra en que aparece. Al establecer la comparación se puede ver la cronología de la estampación.

- Bibliomat. Información destinada a la investigación bibliográfica. Para describir orlas, viñetas y cualquier recurso tipográfico que acompañan al grabado, aunque no forman parte de éste. La identificación de recursos tipográficos puede ser útil para la adscripción a un taller de una obra en la que no se menciona al impresor, para estudiar la pertenencia de los tipos a determinados impresores, etc.

Los dos últimos elementos equivaldrían a una nota general, campo 500 del formato MARC21.

5. Editor del recurso (Publisher). Se reseña el lugar, nombre del impresor y fecha de la obra fuente. Importante para ver la transmisión de tipos y planchas entre impresores, para justificar el deterioro de las planchas por su uso en distintas impresiones, etc. Está demostrado el traspaso de material xilográfico entre impresores incluso entre distintos países. Los primeros grabados de los libros españoles se realizaron con tacos traídos por impresores alemanes $\mathrm{y}$, en menor medida italianos, que se establecieron en la península. Según Lyell (1997, p. 45), hasta 1483 no se puede ver una obra impresa en España en la que el artífice y las ilustraciones fueran totalmente españolas.

6. Colaborador (Contributor). EI LAP de DC lo define como "una entidad (persona, organización o servicio) que tiene alguna contribución en el contenido del recurso". Es una visión más amplia que la del concepto de autor o autoría de las Reglas de catalogación y enlaza con la norma ISBD que incluye como menciones de responsabilidad los "nombres de personas y entidades que tienen alguna participación en el contenido intelectual o artístico de la publicación". Hemos utilizado este elemento para registrar los nombres de grabadores, dibujantes, autores originales y otras participaciones que aparezcan expresadas en el grabado. Para identificar las distintas funciones de dibujante, grabador, etc., mediante las expresiones que aparecen junto a los nombres se ha seguido la metodología de Vives Piqué (2003, p. 138-141). Muchos grabados no tienen esta información, 
por lo que este elemento en la mayoría de los registros contendrá solamente la forma normalizada del nombre del autor de la obra en la que aparece el grabado. Se podría haber incluido también el nombre del impresor de la obra, por cuanto puede ser responsable de la inclusión del grabado en ella, pero se ha preferido para éstos el elemento "Editor".

7. Fecha (Date). Utilizamos este elemento de manera repetida. Una para la "Fecha de publicación" de la obra que contiene el grabado y otra para el "Siglo" al que corresponde. La mención del siglo no está contemplada en el Dublin Core ni en el formato MARC21, pero creemos interesante incluir este dato para poder comparar el tratamiento iconográfico dado a un tema o persona a lo largo del tiempo.

8. Tipo de recurso (Type). Este elemento no tienen contenido en la fase actual del repertorio.

9. Formato (Format). Equivalente a una descripción física del recurso o campo 340 del formato MARC21, hemos utilizado este elemento para registrar la "Técnica" de realización del grabado. Sólamente se hace la distinción entre xilográfico, grabado en relieve con planchas de madera, y calcográfico, grabado en hueco por medio de planchas metálicas, en función de que se vea o no la huella.

10. Identificador (Identifier). Enlace con la "Imagen" digitalizada mediante un identificador propio basado en el nombre de ésta. Se incluye también el "Número" de inventario que tiene cada imagen, que corresponde al orden en que se han digitalizado. Es un elemento de uso interno que se que se mantiene por seguridad y porque sirve de número de registro e inventario.

11. Fuente (Source). Signatura topográfica de la obra en que aparece el grabado. Enlace con el registro del catálogo de la biblioteca poseedora de la obra.

12. Lengua. Este elemento no tienen contenido en la fase actual del repertorio.

13. Relación (Relation). Según el LAP de Dublin Core, "referencia a un recurso relacionado". Hemos seleccionado dos calificadores:

- (HasFormat URI), que utilizamos cuando aparece una imagen que es igual a otra que ya se ha descrito pero está en distinta fuente. Se incluye aquí el número del otro registro y se hace un enlace para poderlas comparar. De esta manera, se han localizado imágenes exactamente iguales presentadas como retratos de distintas personas. Se visualiza como "Igual que".
- (IsReferencedBy), denominado "Refer" en nuestra base de datos. Si el grabado que corresponde a un registro está descrito en algún repertorio anterior, se citará aquí el repertorio y el número que le corresponde en éste, como referencia del grabado. Este campo se puede utilizar también si la referencia que se incluye es la de la obra que se ha utilizado para identificar el contenido del grabado, por ejemplo, la Biblia y el pasaje de ésta que describe la imagen. Sería la referencia del contenido.

14. Cobertura. Este elemento no tienen contenido en la fase actual del repertorio.

15. Gestión de derechos. Nombre de la biblioteca propietaria de la obra fuente, ya que los derechos de las colecciones de fondo antiguo pertenecen a las bibliotecas que los custodian.

Para visualizar la información recuperada en las búsquedas, se ha establecido un formato lógico que presenta en primer lugar toda la información relativa al grabado y después ofrece la del documento fuente. Está basado en la catalogación de partes componentes, anteriormente llamada catalogación analítica, que describe primero la parte y a continuación la fuente. El orden de los datos es el siguiente:

- Datos del grabado: título, grabador/es, fecha del grabado, descriptores, técnica, imagen, número, igual que, y refer.

- Datos de la obra: en (fuente), autor de la obra, impresor de la obra, año, siglo, bibliomat, signatura topográfica, y biblioteca.

\section{Metodología para la descripción y gestión de las imágenes}

Los repertorios de grabados prestan mayoritariamente atención a los aspectos técnicos de éstos y describen su contenido por medio de sistemas de clasificación iconográficos que permiten la recuperación según los temas de las imágenes representadas. No hay un sistema internacional que se haya usado de forma generalizada en los catálogos, pero en las colecciones de carácter artístico los sistemas más utilizados han sido el ICONCLASS (Netherlands Institute for Art History), el GARNIER (1984), publicado por el Ministerio de Cultura francés, y el tesauro publicado por la Library of Congreso. El sistema utilizado, uno de los citados o cualquier otro, y el grado de profundidad a que se haga la descripción dependen de las características de la colección. Normalmente, en las clasificaciones iconográficas se siguen los esquemas de los catálogos de estampas publicados que diferencian entre estampas religiosas (la 
Biblia, Dios, la Virgen y los Santos) y estampas profanas, que incluyen escenas históricas (ordenadas por países y cronológicamente), retratos, vistas de países y monumentos, escenas de costumbres, escenas mitológicas y literarias, estampas científicas, ornamentos, etc. (Díez, 1998, p. 187).

El repertorio digital de grabados en libros antiguos de la Universidad de Sevilla clasifica los grabados en once grupos que permiten precisar mejor el contenido de estas estampas. Son los siguientes: arquitectura, escultura, arqueología, escenas y figuras religiosas, heráldica. emblemas, ilustraciones de carácter científico, ilustraciones de carácter histórico, iniciales y adornos tipográficos, mapas, planos, etc., narración, fábula, mito, otros (por ejemplo, adornos caligráficos), portadas, retratos, usos y costumbres.

No hemos utilizado un sistema de clasificación en este repertorio dada la dificultad de establecer clases al nivel de precisión al que queríamos describir la información. Este trabajo supera las descripciones de un catálogo de estampas, de los cuales hay magníficas muestras en las bibliotecas, realizados por personas más expertas que nosotros en el tema, para ser un instrumento de descripción de imágenes para su observación, estudio o posible reutilización.

Las técnicas de gestión, almacenamiento y recuperación se han desarrollado impulsadas por las tecnologías de la información y la presencia de grandes fondos de imágenes (dibujos, grabados y fotografías) existentes en bibliotecas y archivos. Las bibliotecas tienen importantes colecciones de estampas, porque una cantidad inmensa de grabados son ilustraciones de libros, ya que desde la invención de la imprenta en el siglo XV hasta aparición de la fotografía en el siglo XIX, el grabado era el sistema de ilustración empleado. Otra razón es que los museos (siglo XIX) son posteriores a las bibliotecas y los gabinetes de estampas más importantes se crearon en lo que ahora son las grandes bibliotecas nacionales de Europa, que tienen su origen en el siglo XVII (Díez, 1998, p. 192). Sus colecciones de estampas y grabados son, por tanto, muy antiguas y han estado perfectamente controladas y descritas en sus catálogos. Pero la tecnología ha permitido acceder a las imágenes originales de forma rápida, así como agilizar y facilitar el tratamiento de los documentos en grandes cantidades. Disponemos actualmente de grandes bancos de imágenes con todas las posibilidades que el entorno automático permite para los catálogos que junto a los datos textuales pueden incluir también la imagen descrita.
El tratamiento documental de las imágenes grabadas va a permitir su recuperación tanto en el contexto que se produjeron como en otras situaciones totalmente distintas. Hay una traducción de la imagen a palabras y de éstas a descriptores. La indización de las imágenes es necesaria, aunque se puedan almacenar y visualizar en un banco de imágenes. El proceso de indización de una imagen consiste en identificar los elementos iconográficos, objetos y personas, que aparecen como protagonistas y que forman una unidad de descripción. La asignación de descriptores al contenido de la imagen va a suponer la "traducción" de ésta a un texto que permite su almacenamiento y pertinente recuperación.

El grabado, además de su valor artístico, tiene un componente cultural de comunicación visual, ya que las imágenes podían ser entendidas por todo el mundo, incluidos los analfabetos (García Vega, 1984, p. 13). En este trabajo no entramos en el análisis artístico de las imágenes, porque supera el ámbito documental y requiere unos conocimientos sobre la materia para expresar los distintos matices y contenidos iconográficos e iconológicos que pueden cambiar si se observan desde parámetros mentales y culturales distintos. Hacemos por tanto un análisis iconográfico de la imagen grabada, pretendemos que sea objetivo y está destinado tanto a su estudio y consulta como una posterior reutilización, sin valorar el componente estético ni la denotación.

El análisis iconográfico necesita siempre la utilización de un lenguaje controlado, para evitar la sinonimia y polisemia, por lo que estamos utilizando un tesauro propio que se va creando según se incorporan las imágenes al repertorio y que se ha citado anteriormente.

La descripción de imágenes convencionales, por ejemplo, la Crucifixión, nos permite observar la escena en el entorno que se ha representado. La comparación de las imágenes pone de manifiesto que el escenario, edificios o paisaje del fondo, dista en muchos casos del ser el Gólgota y se adapta al lugar donde está hecho el dibujo o el libro. En otros casos, la recuperación de imágenes descritas con coincidencia total de descriptores nos pone de manifiesto que un grabado se utilizaba repetidamente con un título distinto, incluso atribuyendo el retrato a distintas personas en la misma obra.

El producto final se pretende que sea un repositorio digital accesible a los usuarios mediante Web, donde la información esté descrita por medio de esquemas normalizados de metadatos para la descripción de información digital. 


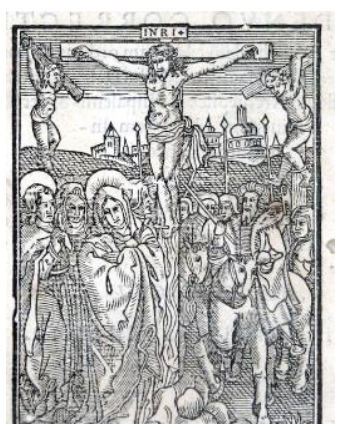

Figura 1. Alcalá de Henares, 1567

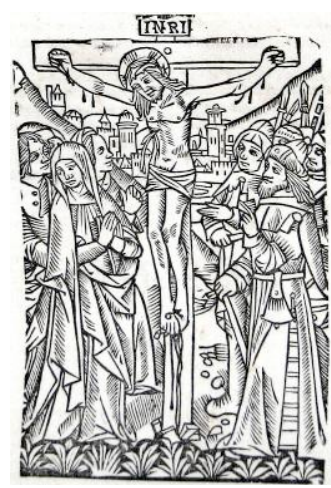

Figura 2. Barcelona, 1598

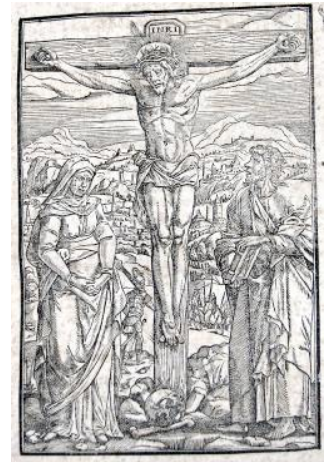

Figura 3. Colonia, 1559

El formato MARC (Machine Readable Cataloging) es el estándar de metadatos utilizado por las bibliotecas, pero la generalización de la información digital a través de Internet ha provocado la aparición de otros formatos más adecuados para ésta. La Dublin Core Metadata Initiative presentó, a principios de los años 90, un conjunto de quince elementos de metadatos descriptivos simples, internacionales e intersectoriales, para satisfacer las nuevas demandas de recuperación, inicialmente para la Web, convirtiéndose en uno de los estándares de metadatos más ampliamente aceptados (FIAB, 2005). Tiene la ventaja sobre MARC que es más sencillo de usar y que las descripciones pueden estar asociadas o incluidas en el propio documento por lo que las consultas son más rápidas y el acceso al documento original puede ser simultáneo, superando la dualidad catálogo/documento de los sistemas tradicionales.
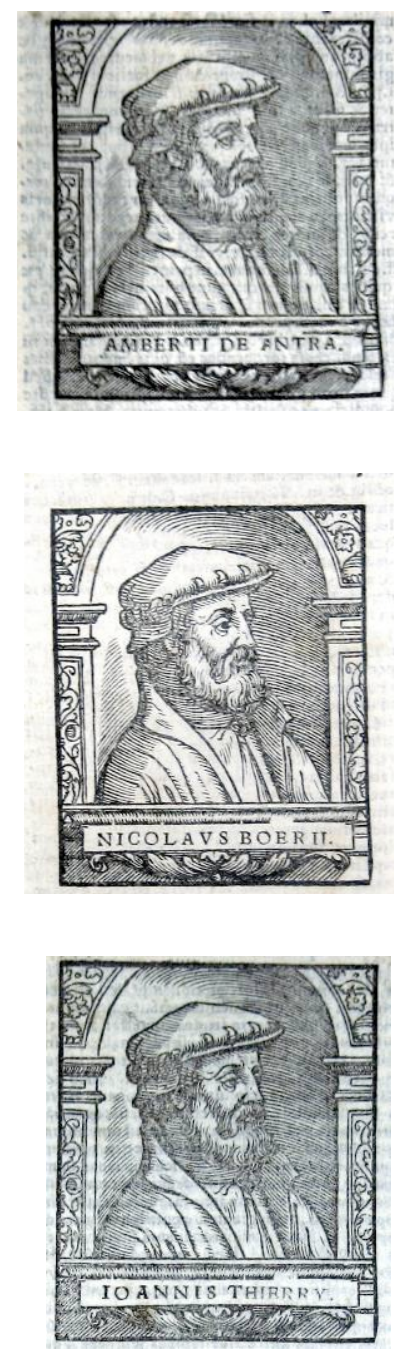

Figura 4. El mismo grabado para ilustrar personas diferentes

Una de las tareas necesarias para la construcción de nuestro repositorio digital es la exportación de los documentos (registros) en Knosys a documentos en sintaxis $\mathrm{XML}$, el estándar de facto para la representación de descripciones de metadatos de recursos digitales en Internet (Hunter, 2003). Para cada registro generamos un documento en XML con las etiquetas y atributos DCQ correspondientes.

Para la construcción del repositorio digital disponemos de diferentes herramientas, algunas de ellas open source como DSpace, Fedora o Greenstone. 
DSpace es una herramienta open source para la construcción de repositorios de información digital (almacenamiento, indización del contenido y difusión), resultado de la colaboración entre las Bibliotecas del MIT (MIT Libraries) y Hewlett Packard Research Labs. La finalidad principal del repositorio es que los metadatos asociados a cada documento (denominado objeto, que puede estar formado por más de un fichero físico) puedan ser expuestos y recuperables mediante el protocolo OAI-PMH. Es la herramienta preferida en España para la implementación de repositorios digitales (Rodríguez Mateos, 2007).

La Biblioteca Universitaria de la Universidad de Murcia también ha implementado mediante DSpace el depósito digital abierto de las publicaciones de Universidad la Universidad de Murcia "Digitum". La elección de DSpace para nuestro repositorio está influenciada por esta implantación de DSpace en la Universidad de Murcia, considerando la futura integración de nuestra colección de grabados en Digitum

El modelo de información de DSpace se configura mediante comunidades, colecciones, elementos y Bitstreams. Las comunidades representan unidades de una organización, las colecciones (y subcolecciones) son agrupaciones de elementos, Los elementos (ítems) son objetos lógicos de contenido que reciben un identificador persistente (handle) y compuestos por bitstreams (ficheros individuales) que reciben tratamiento de preservación. En nuestro proyecto, cada ítem se corresponderá con el registro de un grabado y el fichero de imagen correspondiente se convertirá en un bitstream de ese objeto lógico.

DSpace incorpora Dublin Core Calificado como esquema básico de metadatos descriptivos (Qualified Dublin Core, basado en el Library Application Profile). Además gestiona metadatos administrativos (en Dublin Core) y metadatos técnicos y de preservación (tipo MIME, nombre, tamaño y fecha de creación del fichero, MD5 checksum). Todos estos metadatos se pueden de empaquetar en formato METS (Metadata Encoding and Transmission Standard), un estándar para la codificación de metadatos descriptivos, administrativos y estructurales relativos a objetos en una colección digital, expresados mediante XML. Esta posibilidad facilita el intercambio de colecciones con otras herramientas de construcción de bibliotecas digitales (como Greenstone) o repositorios digitales (como Fedora).

Este conjunto de metadatos refleja la influencia del Modelo OAIS (Open Archival Information Systems) en el diseño de DSpace: es un reposi- torio para contener AIPs (Archival Information Packages), que contienen información descriptiva (metadatos DCQ), información de representación (metadatos técnicos sobre ficheros digitales) e información de contenido (objetos digitales). Un AIP de DSpace se corresponde con un fichero METS (Smith, 2003).

La implantación de un sistema DSpace para nuestra colección de grabados implica en primer lugar la instalación de PostgreSQL (como sistema de gestión de bases de datos relacional) y de Apache Tomcat (un servidor web que funciona como contenedor de Java Server Pages, la tecnología utilizada para el desarrollo de DSpace). Para la personalización a nuestras necesidades se modificó la configuración básica (nombre del repositorio, idioma, índices de búsqueda...), la apariencia global (cabecera, barra de navegación, etc.), el formato de visualización simple de los elementos, los índices de búsqueda y navegación y el formulario de envío de registros de grabados.

Para la importación de los registros a la colección de grabados en DSpace se utiliza la utilidad "Itemlmport". Es necesario disponer de una estructura jerárquica de directorios: un directorio principal contiene un subdirectorio por cada registro a importar. En cada subdirectorio se crea un fichero de texto que contiene el nombre del fichero de imagen, y se copia el fichero XML con las descripciones en Dublín Core y el fichero con la imagen del grabado.

\section{Resultados}

Se ha planificado el trabajo para que al final de 2008 se puedan incorporar a la biblioteca digital los grabados de la Biblioteca Universitaria, los cuales se habrán sometido a todas las etapas metodológicas y serán accesibles sin restricciones. Posteriormente se pretende abordar la Biblioteca Regional, la biblioteca del Archivo Municipal de Murcia y otras de menor contenido en fondos antiguos, como el I. E. S. Alfonso X el Sabio.

Actualmente, por tanto, solo se pueden ofrecer resultados parciales del proyecto. Se han digitalizado más de 900 grabados de la Biblioteca Universitaria de Murcia que corresponden al siglo XVI y parte del XVIII. Se han descrito completamente en la base de datos de Knosys solo 200 , para poder evaluar la recuperación y validar el funcionamiento de los descriptores.

La recuperación de la información parece que está siendo pertinente y fiable a través de los datos utilizados. Como éste es un proyecto a largo plazo, habrá que estudiar si, además de 
los descriptores utilizados para describir el contenido de las imágenes, es necesario agrupar éstas según un sistema de clasificación más amplio, al igual que ha hecho, por ejemplo, la Universidad de Sevilla. Conforme el número de imágenes vaya creciendo, se podría establecer una clasificación amplia que agrupara los grabados en religiosos, profanos, mapas y planos, monedas, heráldica, retratos y otros que se consideren oportunos.

\section{Referencias}

Biblioteca Nazionale Centrale di Roma. MAR.T.E.: marche tipografiche editoriali. http://193.206.215.10/marte/ index.html (2007-11-05).

Díez Carrera, C. (coord.) (1998). Los materiales especiales en las bibliotecas. Gijón: Trea, 1998.

Dublin Core Metadata Initiative. Library Application Profil. (Realizado por) Rebecca Guenther http://dublincore.org/ documents/library-application-profile/ (2008-05-24).

Federación Internacional de Asociaciones de Bibliotecarios (2005). Directrices para proyectos de digitalización de colecciones y fondos de dominio público, en particular para aquellos custodiados en bibliotecas y archivos. Madrid: Ministerio de Cultura, Dirección General del Libro, Archivos y Bibliotecas, 2005.

García Vega, Blanca (1984). El grabado del libro español: siglos XV, XVI, XVII (aportación a su estudio con los fondos de las bibliotecas de Valladolid). Valladolid: Institución Cultural Simancas, 1984.

Garnier, François (1984). Thesaurus iconographique: système descriptif des représentations. París: Le Léopard D'or, 1984.

Hunter, J. (2003). Working towards MetaUtopia: a survey of current metadata research. Library Trends. 52:2 (2003) 318-344. http://www.itee.uq.edu.au/eresearch/papers/ 2003/LibTrends_paper.pdf (2007-06-23.

Library of Congress. Prints and Photographs Division (1995). Thesaurus for graphic materials. Washington, D.C.: Cataloging Distribution Service, Library of Congress, 1995.

Library of Congress. Devlopment an MARC Standars Office. MARC to Dublín Core Crosswalk. http://www.loc. gov/marc/marc2dc.html (2008-05-24).

LyelL, James P. R. (1997). La ilustración del libro antiguo en España. Edición de Julián Martín Abad. Madrid:Ollero y Ramos, 1997.

McKerrow, Ronald B. (1998). Introducción a la bibliografía material. Madrid: Arco Libros, 1998.

National Library of the Netherlands. Watermarks in Incunabula printed in the Low Countries (WILC. http:// www.kb.nl/bc/incun/watermerken.html (2007-11-05).

Netherlands Institute for Art History. ICONCLASS. http://www.iconclass.nl/ (2008-05-27).

Páez, Elena. (1981-1983) Repertorio de grabados españoles en la Biblioteca Nacional. Madrid : Ministerio de Cultura, Dirección General del Libro y Bibliotecas, 19811983, 4 v..

Prendes Espinosa, M. P. (1998). El lenguaje de la imagen. Murcia: DM, 1998.

Rodríguez Mateos, D.; Bueno de la Fuente, G.; Hernández Pérez, A. (2007). DSpace: implantación inicial como herramienta para la gestión de un repositorio abierto institucional. Actas de la $I^{\text {a }}$ Jornada de Software Libre para servicios y unidades de información. Santiago de Compostela, 10 de mayo de 2007. http://hipatia.uc3m. es:8080/dspace/bitstream/2316/76/1/dspace-uc3m-jsof tlibre07.pdf (2007-06-23).

Smith, Mackenzie. (2003). METS Repositories: DSpace; a presentation at METS Opening Day. Library of Congress, October 27-28, 2003. http://www.loc.gov/standar ds/mets/presentations/msmith2.ppt (2007-06-23).

Universidad de Murcia. Digitum: Depósito Digital Institucional de la Universidad de Murcia. http://digitum.um.es/ dspace/ (2008-05-02).

Universidad de Murcia. Biblioteca Universitaria. Biblioteca digital, portadas y colofones. Siglos XVI-XVIII. http:// gargoris.cpd.um.es/cgi-bin/abweb/X6147/ID27762/G0 (2007-11-06).

Universidad de Sevilla. Fondos digitalizados de la Universidad de Sevilla. Grabados. http://fondosdigitales.us.es/ books/plates/ (2008-05-12).

Universitat de Barcelona. Marques d'impressors. http://eclipsi.bib.ub.es/imp/ impcat.htm (2007-11-05).

University of Florida. Printer's Devices. http://web.uflib. ufl.edu/spec/rarebook/devices/device.htm (2007-11-07).

Valle Gastaminza, Félix (1993). El análisis documental de la fotografía. // Cuadernos de documentación multimedia. 2 (1993) 43-56.

Vives Piqué, Rosa (2003). Guía para la identificación de grabados. Madrid: Arco Libros, 2003. 